JOHN M. WATANABE

Department of Anthropology

Dartmouth College

Hanover, NH 03755

Barbara B. SMUtS

Department of Psychology

University of Michigan

Ann Arbor, MI 48109

\title{
Explaining Religion without Explaining It Away: Trust, Truth, and the Evolution of Cooperation in Roy A. Rappaport's "The Obvious Aspects of Ritual"
}

\begin{abstract}
Moving beyond the ecological functionalism of Pigs for the Ancestors, Roy Rappaport's subsequent work on ritual explored how the "obvious aspects" of ritual's formalism and the need to perform it literally embody in its performers expressions of sanctity and truth that counter the threats of lying and alternative inherent in symbolic communication. He recognized that symbolic meaning and truth presuppose social cooperation and trust between individuals, and ritual serves uniquely to reaffirm this mutuality at the level of both individual behavior and conventional meaning. Through a study of male greetings among olive baboons (Papio cynocephalus anubis), this paper illustrates how ritual in Rappaport's sense may indeed intensify cooperation in socially complex but nonlinguistic contexts by establishing a behaviorally transparent means of certifying otherwise opaque individual intentions. Thus, not only may ritual sanctify symbolic communication, but it also may have played a crucial role in its evolution. [ritual, sociocultural evolution, religion and society. symbolic communication, olive baboons, primate social behavior]
\end{abstract}

$\mathbf{R}$ oy A. Rappaport remains most widely known for his seminal work in ecological anthropology, especially the role he attributed to ritual pig feasting and warfare in regulating the size of human and animal populations among the Tsembaga Maring of highland New Guinea. This early work involved a functionalist analysis of ritual within a largely imputed social and ecological system (Biersack, introduction, this issue). From the first, however, Rappaport recognized that such neo-functionalist analyses alone failed to account for the ritual form by which the Tsembaga ordered their interactions with the social and natural world. In asking what made ritual a particularly apt vehicle for fulfilling the functions he attributed to it, Rappaport turned increasingly from functionalism to formalism (Wolf, this issue). That is, he sought to trace out the logical consequences of ritual's outwardly distinctive features, especially the way ritual's highly stereotyped behaviors and the need to perform them could counter the potential for lying and deceit inherent in symbolic communication. While Rappaport focused specifically on the relationship of ritual form and performance to sanctity-that is, unverifiable yet unfalsifiable para- digms for conventional associations between signs and their significata-his approach also highlighted the way ritual behavior could make social communication between individuals more reliable. Indeed, he suggested in passing that ritual may have played a crucial evolutionary role in intensifying the complex, reciprocal relationships of mutual trust that symbolic communication and social action presuppose.

To investigate this possibility, we spent the summer of 1983 traversing a small comer of Kenya s Rift Valley in pursuit of a troop of savanna baboons. We wanted to study why adult males greeted by mounting one another or trying to pat each other's testicles, and whether these behaviors reflected further social cooperation between them. This curious focus arose innocently enough one day in the spring of 1982, when Barbara Smuts, then lecturing on primatology in the anthropology department at Harvard, invited John Watanabe to watch a film in which a youthful, cleanshaven Irven DeVore described a "central hierarchy" of three adult male baboons who dominated the troop of olive baboons (Papic (vno(ephalus anubis) he had studied in Nairobi National Park during the late 1950s and early 
1960s (Education Development Center 1965). When Watanabe asked how these males formed their alliance, Smuts responded that no one had yet looked at this, although she surmised that a certain kind of greeting behavior between males might play a role. Having recently read Rappaport's essays on "The Obvious Aspects of Ritual" (1979b) and "Sanctity and Lies in Evolution" (1979c), Watanabe suggested that Rappaport's approach might shed light on how, and perhaps even why, formalized gestural greetings could serve to coordinate and establish trust between the males engaging in them.

Like all exchanges between social and biological anthropologists at Harvard in those days, our discussion soon foundered on how to reconcile neo-Darwinian concerns with the pursuit of individual reproductive interests and enduring Durkheimian insistence on the constraints social conventions imposed on individuals engaged in cooperative or reciprocal relations. Although neither of us held to a strict genetic or cultural determinism, the discontinuities between evolutionary and cultural theory left us facing the age-old conundrum of the individual in society: evolutionary approaches tended to envision society as a byproduct of ecological forces that drew autonomous, self-interested individuals together, while culturalist perspectives tended to treat individuals largely as creations of the sociocultural orders they inhabited.

Rappaport's approach crosscut this dichotomy. He argued that, far from an arbitrary trapping incidental to its behavioral or symbolic content, the ritual form itself constituted a conventionally given context within which individuals acted out their cooperative intentions toward each other through mutually coordinated social action. While clearly recognizing the distinction between "ritual" as formalized behavior and "rituals" as culturally constituted events (1979b:176), Rappaport perceived in both a simple but extremely powerful formalism capable of transforming individual behavior into meaningful social action in the Weberian sense of reciprocal interactions imbued by actors with intention and significance.

After due deliberation, we agreed that greetings between male baboons might represent a revealing instance of ritual in just this sense: although neither the cause of social cooperation or individual intentionality, nor a sufficient condition for the emergence of symbolic communication, ritual formalism and performance in Rappaport's terms suggested a plausible mechanism by which already social yet highly competitive individuals such as male baboons could convey intentions and perhaps even promises to one another within a socially complex yet nonlinguistic behavjoral context. As such, we postulated that Rappaport's theory of ritual might provide a way of relating these baboon greetings to the evolution of symbolic communication, not in any necessary causal sense but in the sense that ritual constituted an evolutionarily available, behaviorally flexible means by which social cooperation could have intensi- fied into language and culture in conjunction with other phylogenetic changes in hominid cognition and self-consciousness. Conversely, it could also provide a way of appreciating the complexity of nonhuman primate social behavior.

In this paper, we thus examine the significance of Rappaport's theory of ritual for transcending long-standing dichotomies in evolutionary and cultural theory between individualist and culturalist explanations of self and society, or, as Biersack has put it (this issue), the idealist-materialist impasse in anthropological conceptions of culture (cf. Rodseth 1998). In comparing ritual in nonhuman animals and human cultures, we seek here not to equate the two but to ascertain the extent of their similarities in order to understand better the processes by which the differences between them might have emerged. Such an exercise may prove useful in reminding ethologists that ritualized interactions can involve complex communication about future social action, and symbolically minded anthropologists that cultural forms and meanings remain rooted in enduring problems of social cooperation between willful individuals.

We begill with a brief discussion of ritualized behavior in nonhuman animals, then turn to what in Rappaport's formulation sent us to the baboons. We next describe male baboon greetings and discuss our findings and their implications for ritual's role in intensifying social cooperation and trust in the evolution of symbolic communication. In the conclusion, we return to Rappaport's theoretical work and its implications for grand Durkheimian questions about the role of religion in constituting society-questions that advances in symbolic and ideological approaches to religion over the last thirty years have ironically tended to obscure or ignore, if not categorically deny.

\section{Ritualized Behavior in Nonhuman Animals}

Animal behavior falls roughly into two types-instrumental actions that alter the animal's environment in ways that contribute directly to survival or reproduction, and communicative actions that typically involve little or no manipulation of the physical environment but instead convey information to specific individuals, usually members of the same species. Ethologists have long recognized that communicative actions, usually referred to as "displays" or "signals," often include highly stereotyped, exaggerated, or repetitive behaviors. Researchers originally believed that many of these signals were innate becallse of their relative uniformity across different members of the same species and their highly predictable contexts of use. Detailed study of ritualized signals, however, indicates that they, like many other aspects of behavior, involve both an evolutionary predisposition and individual modification through experience, including, in some species, enculturation (Smith 1977). 
Building on Darwin's observations (Darwin 1872), Julian Huxley (1914) was the first to propose that highly stereotyped signals evolved by natural selection the same way more instrumental behaviors did. He coined the term rituali-ation to refer to the process by which selection gradually alters certain behaviors into increasingly effective signals. European ethologists, like Tinbergen (1952) and Lorenz $(1950,1966)$, pioneered the study of ritualized behavior in nonhuman animals, particularly in fish and birds, but subsequent research has also identified ritualized signals in mammals, including nonhuman primates (Hinde 1974; Moynihan 1956; Smith 1977).

A familiar example of ritualization involves the way domestic dogs lick their human associates in greeting. Among wolves, the ancestors of domestic dogs, subordinate adults greet dominant members of the pack by nipping and licking the mouth area. Researchers hypothesize that this greeting derives from the begging behavior of canid pups, who touch their muzzles to the mouth area of adults in order to induce regurgitation of well-chewed pieces of meat (Mech 1970; Schenkel 1967). This example illustrates three essential aspects of ritualization (Smith 1977). First, a behavior that originally served a specific utilitarian function appears in a new social context. Second, in this new context, the behavior typically becomes simplified, exaggerated, and stereotyped. Third, the new function of the behavior has less to do with achieving immediate, instrumental ends than with signaling an attitude or intention that, in turn, may influence the behavior of another individual.

At one extreme, these social signals take the form of highly stereotyped "one-way" displays meant to elicit a simple response from the recipient, as in aggressive displays by territorial birds that warn off potential intruders. At the other extreme, more complex ritualized behaviors demand cooperation between two or more individuals who exchange often elaborate signals. Wilson (1975:224) terms such exchanges "ceremonies" and sees them as "a highly evolved set of behaviors used to conciliate and to establish and maintain social bonds." For instance, potential foes who interact repeatedly, such as males inhabiting neighboring territories, may settle disputes through "ritualized fightilig" or "agonistic displays"; potential mates develop mechanisms of tolerance and social coordination through "courtship displays."

As Smith (1977:426-427) writes, such formalized interactions are

predictable in general pattern ... rules constrain the participants to acconmodate to each other to begin, sustain, and (in some cases) to complete the interaction. ... [Each participant is allotted] a predetermined set of parts or roles from which to select: each part deternines a range of moves and responses that must or may be perlorned. In being perforned, the parts jointly affect each other in orderly ways that lit within the interactional format. .. [The interaction] employs a very fixed repertoire of component acts ... |and proceceds) in a proh- abilistically predictable fashion... [ [The rules of interaction] are specific to the ... kind of interactional activity: they "frame" it, fitting the actions of its participants to its organization.

Smith goes on to point out, however, that within any such formalized program or framework, participants can exercise "a great deal of freedom of detailed behavior" (1977: 426).

In addition to this formal framing, Smith (1977:428) makes the crucial observation that the component behaviors of nonhuman animal displays pertain directly to the ritual performance itself, not to some external referent. In the wolf greetings mentioned above, the stereotyped display of licking the muzzle of dominant animals reflects the immediate context of greeting, not the gesture's possible antecedents in feeding behavior or parent-offspring relations. Similarly, despite the presumption of events, actions, and authorities beyond their bounds, human rituals retain the same immediacy—or what semioticians call "indexicality" or "self-referentiality." That is, the proper and efficacious sacrifice to a guardian spirit, for example, depends on precise and prescribed use of ritual objects and observances, not literally manipulating the cropland the spirit is supposed to protect, much less the spirit itself.

Several characteristics thus emerge from nonhuman animal rituals that suggest the evolutionary substrate they constitute for human cultural rituals. First, they draw on gestures or behaviors from other social contexts and recombine them into distinctive displays or signals. Second, these recombined displays relate not to instrumental activities but to social communication, most often with conspecifics. Third, these displays become ritualized to the extent they circumscribe a repertoire of possible behaviors and establish a formalized framework of interaction recognized as such by participants through their volitional conformity to these constraints. Finally, these displays remain rooted in the here-and-now and literally embody in participants whatever mutual coordination they entail.

Significantly, it is precisely on these grounds that Rappaport begins his analysis of ritual, working not from ethological data but from his own "formal-causal" model derived from the "logically necessary" entailments of the ritual form itself (1979b:173-174). We now turn to Rappaport's analysis of these obvious aspects of ritual.

\section{Ritual Form and Performance}

Rappaport argues that there are two obvious aspects of ritual (1978b:175-179). First, ritual consists of more or less invariant sequences of acts and utterances that the participants themselves do not invent but to which they must conform. Second, in order to hatve a ritual at all, participants must actually perform the'se sequences rather than simply invoke or acknowledge then. Ritual's formalism, commonly expressed in its stylized, stereotypic actions and 
fixed sequences, not only sets ritual off from everyday behavior but also imposes a standard of conduct beyond the will of its individual participants. By so holding individual performers to a mutually induced conformity, ritual formalism begets behavioral invariance, and mutually enacted invariance can become iconic representations of interindividual reliability, certainty, and perhaps even truth (1979b:208-211).

In sum, ritual is unique in at once establishing conventions, that is to say enunciating and accepting them, and in insulating them from usage. In both enunciating conventions and accepting them, it contains within itself not simply a symbolic representation of social contract, but a consummation of social contract. As such, ritual ... is the basic social act. [1979b:197, emphasis in the original]

Similarly, the second prerequisite of having to perform a ritual demonstrates participants' acceptance of its conventions because they must literally act them out. Although such acceptance need say nothing about the performers' sincerity (much less their belief) in what they perform, conformity to ritual's dictates represents a clear public acceptance of commonly agreed-upon standards of performance, not simply willful individual behavior (1979b: 193-195). These standards, however rudimentary, enacted within a clearly delimited here-and-now, literally embody in ritual performers their mutual acceptance of an agreedupon form on which further social cooperation might subsequently be built. At the same time, this tangible experience of mutual conformity constitutes inclusion within a larger whole, which can come to hold positive rather than simply coercive import, as reflected in the emotionally persuasive "numinous" force often associated with ritual (1979b:211-213; 1979c:234-238). ${ }^{1}$

In tracing out the logical entailments of ritual form and performance, Rappaport focuses primarily on how ritual ameliorates the problems of lying and alternative within systems of symbolic communication, the very flexibility of which makes truth-and therefore the trustworthiness of communications-problematic. The genius of his approach lies in recognizing that symbolic meaning and truth presuppose social cooperation and trust between individuals, and ritual serves powerfully to intensify and reaffirm this mutuality on a behavioral, not just symbolic, level. Indeed, such willing coordination of behavior can itself become a prototype of promising (cf. 1979b: 188-194).

Ritual's most obvious features of behavioral form and performance thus precipitate a microcosmic social order, minimally - but therefore unequivocally_-defined by mutually constrained acts and interactions in which performers can simultaneously make and keep promises to each other simply by coordinating their actions and performing the ritual. Clearly tautologous, such speechless yet public promising never guarantees further social compliance, but it can at least suggest the possibility of future cooperation.
It can also make performers liable for punishment if they violate whatever expectations they or others come to associate with their performance. Unable to insure absolute trustworthiness, ritual can still establish grounds for moral indignation-and righteous retribution-should presumed promises prove false.

For Rappaport, it is the behavioral simplicity, not the symbolic elaboration, of ritual that lies at its core and enables otherwise autonomous individuals to communicate their willingness to cooperate with each other even in the absence of language. Ritual formalism and performance in and of themselves can accord "mere" individual behavior the potential of conveying intent and implication essential to true social action. As Rappaport argues, "The invariance of ritual, which antedates the development of language, is the foundation of convention, for through it conventions are not only enunciated, accepted, invested with morality, and naturalized, but also sanctified" (1979b:211). Consequently, "It is plausible to suggest . . that ritual, in the very structure of which authority and acquiescence are implicit, was the primordial means by which men, divested of genetically determined order, established the conventions by which they order themselves" (1979b:197).

Although Rappaport says that his argument rests on "logical necessity rather than empirical demonstration" (1979b:173), the evolutionary priority he grants to promise and trust in ritual form and performance, over meaning and truth in cultural symbols, admits possible, if necessarily indirect, investigation. If ritual does indeed represent "the basic social act," then we expected that greeting rituals between adult male baboons might well relate directly to their formation of cooperative alliances. This expectation, however, carried four caveats: first, although we clearly had the evolution of human rituals (and Culture with a capital " $C$ ") in mind when formulating our research, our choice of baboons implied nothing about which model of contemporary primate social organization we think best applies to our hominid ancestors. The millions of years and reticulated phylogeny separating us from even chimpanzees as our nearest living primate relatives, to say nothing of even more distantly related baboons, make it impossibly naive to project the social behavior of any living primate directly back into our hominid past (cf. Moore 1994).

Second, we did not presume that ritual alone caused the evolution of human language and culture. If it had, why then might baboons have rituals but no spoken language or elaborate culture of their own? Clearly, other phylogenetically derived capacities of early hominid perception, reason, and memory crucially influenced the evolution of human symbolic communication, but ritual maly have constituted an important social (not just physical) environment that selected for such capacities and enabled hominids to intensify interindividual cooperation into more complex, increasingly conventionalized, systems of symbolic communication. 
Third, male baboon greetings clearly lacked components of human ritual, especially sanctity as Rappaport discusses it. In the spirit of Rappaport's logically necessary argument, however, we surmised that when found in a social context of recognizable individuals capable of intentional social action, ritual form and performance might serve to allay the unavoidable and enduring suspicions inherent in social cooperation and thus lay important groundwork for the trust essential for the evolution of symbolic communication.

Finally, our focus on male greeting rituals presumed nothing about the gendered origins of language and culture. We chose male greetings because of their striking incongruity with the otherwise relentlessly aggressive, competitive behavior of male baboons. The greetings also appeared to serve little immediate utilitarian purpose, in contrast to, for example, grooming among females, and, indeed, they placed male greeters at considerable risk in the hands of their partners. This seeming inconsistency further suggested the greetings' communicative aspects. As discussed below, male greetings reflect other stylized interactions between baboon mothers and infants and mating pairs of males and females. If ritual does indeed play a role in fostering male baboon cooperation, it is undoubtedly because other kinds of cooperation involving mother-infant pairs and mates (and the rituals members of these dyads have with each other) have provided males with a repertoire of potential behaviors on which to draw for their greetings. If we neglect these other rituals, it is because our intent here lies in substantiating a formal aspect of Rappaport's theory, not in establishing a substantive point of departure for the evolution of culture and language.

\section{Testes and Testament in Baboon Greetings}

To the extent of its limited duration, our four-month study bore out our suppositions about the relationship between male greetings and alliance formation in this troop of savanna baboons (cf. Smuts 1985). ${ }^{2}$ The male greetings we observed clearly constituted rituals in that they consisted of readily identifiable, formalized gestures that set them apart from other kinds of interactions. A greeting typically began when one male approached another with a rapid, exaggerated rolling gait. The approaching male would look directly at the other and often lip-smack (a friendly gesture) while making a "come-hither" face (Strum 1987) with ears back and eyes narrowed-a baboon equivalent of the human raised eyebrow greeting. The second male sometimes avoided the approach or rejected it by turning away, in which case the first male ceased his approach; other times, the approaching male himself veered away. More commonly, the second male accepted the approach by maintaining eye contact and often lip-smacking and making the come-hither face in return.
Upon approaching, the males would exchange a series of gestures that could include presenting the hindquarters (rotating the body so that the hips faced the other male), grasping the hindquarters with one or both hands, mounting, touching the scrotum, pulling the penis, and, less often, face-to-body nuzzling or, rarely, embracing. Usually, the roles adopted during a single greeting remained asymmetrical, with one male taking the more active role. Occasionally, a mutual exchange occurred, as when each touched the other's scrotum simultaneously or in rapid succession. Immediately after the exchange, one (or occasionally both) of the males would move rapidly away using the same rolling gait characteristic of the approach. The entire sequence took no more than a few seconds. Either male could break off the greeting at any time simply by moving away, and occasionally (seven percent of the greetings we recorded) attempts to greet ended in threats, chases, or fights (Smuts and Watanabe 1990:152-153). Remarkably, however, of the 637 greetings documented in our study (as well as roughly 400 additional male-male greetings recorded on videotape by Smuts in 1993), not one resulted in a discemible injury.

The significance of these greetings lies in the fact that virtually all other interactions between male baboons involve antagonistic exchanges. Male baboons most typically threaten, chase, and attack one another. Outside the greetings, they almost never engage in friendly behaviors, like lip-smacking or grooming, and when one male approaches another, the other usually avoids the approach or threatens the approacher. Fights routinely occur, as do minor wounds, and serious wounds are not uncommon. Such mutual hostility may explain why greetings typically occur in a neutral social context as males peacefully forage, travel, or rest, and why males wishing to greet adopt their highly stylized approach. The absence of a contested resource and the approaching male's distinctive posturing enable dominant males to move toward subordinates without evoking an avoidance response and subordinates to move toward dominants without risking attack (Smuts and Watanabe 1990:159).

The frequency and nature of the greetings varied depending on the types of males involved. To make sense of this variation, it is important to note that olive (savanna) baboons have a female-bonded social organization in which females, their daughters, and granddaughters form the permanent core of the troop, while males transfer out of their natal troops and into other troops as adolescents or young adults. ${ }^{3}$ The 12 fully adult males in our troop comprised two classes. Older residents ("old males") included nonnatal males past their physical prime who had lived in the troop for at least two years, usually much longer. "Young males" in their physical prime had either recently transferred into the troop or were natal males who would all eventually transfer to other troops. Based on the outcomes 
of dyadic agonistic encounters, all young males individually outranked all old males.

Among baboons in general, higher-ranking males mate more often with estrous females than do lower-ranking males, but in this population of baboons, lower-ranking, older residents tend to mate as often, or more often, than their higher-ranking counterparts (cf. Bulger 1993). This was the case during our study: the median sexual consort score for old males was slightly higher than the median score for young males. Lower-ranking males achieved this unexpectedly high mating success by forming coalitions in which they jointly harassed males in consort with fertile females until a consort turnover occurred. All of these challenges targeted young males; we never saw old males challenge one another's consortships. After the turnover, the female almost always ended up with one of the old males involved in the coalition. Over the long term, old males gained females in rough proportion to the frequency with which they participated in coalitions (Berkovitch 1988; Smuts and Watanabe 1990). Thus, although young males individually possessed superior fighting ability, old males compensated for any physical disadvantage by cooperating with one another (Smuts and Watanabe 1990; cf. Bulger 1993).

Greetings tended to reflect these social dynamics. If they occurred at all, greetings between young adult males almost always displayed considerable tension. Young adult males had the lowest percentage of completed greetings (one-third) because they often circled one another, jockeying over who was going to do what to whom, often without success; incomplete greetings resulted. Young males never formed coalitions with one another and, except for their attempted greetings, studiously avoided interacting with each other or even associating with the same females. In contrast, the older, long-term resident males who formed coalitions with each other tended to have relatively relaxed greetings, and they completed most (two-thirds) of them. Old and young males also greeted, with the younger, higher-ranking male almost always initiating and taking the more active role, usually by mounting or grasping the other male's hindquarters, and occasionally by touching the other male's genitals. While this asymmetry in roles may have simply reflected the already clear-cut dominance relationships between young and old males, it seemed to us that, at least some of the time, young males sought in these greetings to establish relations with older males who, by virtue of their affiliative relationships with females, infants, and other old males in the troop, might prove the most valuable allies (Smuts and Watanabe 1990:162-163; cf. Smuts 1985).

Although these patterns generally applied, particular dyads demonstrated distinctive greeting styles. For example, the two highest-ranking nuales, at the time engaged in a tense standoff for the dominant position, repeatedly attempted to greet, but we never saw them succeed because neither appeared willing to take on the passive role. Another pair of males, Alex and Boz, greeted much more often than any other pair in the troop. These old males, unrelated but familiar to one another after seven years of living together in this troop, had the longest-standing, most reliable alliance of any pair of males and routinely helped each other take fertile females away from younger rivals. Unlike all other male pairs, neither tried to dominate the other, and they remained the only pair of males observed defending one another in fights with other males. In contrast to the asymmetry of greeting roles characteristic of most male-male dyads, their greeting roles reflected nearperfect symmetry. Indeed, whenever we saw them greet twice in rapid succession, the male who took the active role in the first greeting initiated the subsequent greeting by graciously inviting his partner to adopt the active role. They apparently sought purposively to have their greetings parallel their turn-taking in the context of coalitions.

Several points bear noting. First, since these baboons represent a female-bonded species, adult males spend much of their lives interacting with unrelated and initially unfamiliar others. Consequently, male-male cooperation should occur less often than in male-bonded primate species, such as chimpanzees, in which male philopatry (continuing residence in the natal troop) facilitates cooperation both evolutionarily through kin selection and developmentally through long-term familiarity (Goodall 1986; Nishida and Hosaka 1996). Savanna baboons represent one of the most striking exceptions to this generalization. They are the only known female-bonded species in which older males routinely form aggressive coalitions against younger males as a way of acquiring mating opportunities (Smuts 1987:390).

Second, such female-bondedness highlights the dilemma faced by a slightly over-the-hill male baboon whose canines have dulled, whose speed and stamina have waned, yet who nonetheless remains perfectly able-and highly motivated - to mate with as many fertile females as he can. To do so, however, he must risk injury or even death from younger, stronger rivals whose two-inch-long, razor sharp canines easily rank among the most lethal weapons on the African savanna. Alternatively, he can choose to settle into a tranquil but mostly celibate middle age or ally himself with other older males and together challenge the individually dominant younger males. The second alternative would appear more desirable, but his potential allies consist of the very rivals whom he has long tried to cow through incessant harassment, bluffs, counterbluffs, deception (Byme and Whiten 1990), and the occasional bloody battle (Sinuts 1985:151-155). The dilemına for these males centers on how to overcome this legacy of mutual antagonism, manipulation, and deception in order to establish reliable, mutually beneficial, cooperative relationships." 
Here the greeting rituals can play a decisive role. When one male moves toward another with the distinctive gait and gestures that characterize greetings, he communicates unambiguously that the purpose of his approach lies in neither contesting a resource nor initiating a fight but in entering into relatively low-risk negotiations concerning the current, and possibly future, state of his relationship with the other male. If the other male responds appropriately through eye contact, lip-smacking, and the come-hither face, he communicates the same intentions. As mentioned above, none of the greetings we observed among adult males resulted in a wound. ${ }^{5}$ In contrast, when engaged in high-stakes contests over resources, males routinely inflict injuries on each other. Thus, through mutual enactment of the ritual form, male greeters appear to establish a temporary truce or neutral ground on which to explore, or even constitute, relations between them with minimal risk of injury. Furthermore, the various gestures that occur may indicate how far negotiations have gone. We suspect that, more often than not, greeting partners achieve only the most rudimentary accommodation of an uneasy truce. Occasionally, however-and perhaps only after greeting repeatedly over an extended period of time-males like Alex and Boz overcome their inherent rivalry and develop truly cooperative relationships that give them a considerable advantage over those males less successful in coordinating their actions.

Several lines of evidence support this interpretation. First, as exemplified by Alex and Boz, quantitative evidence indicates that pairs of males whose greetings demonstrate reciprocal symmetry of roles form coalitions significantly more often than expected and are opponents less often than expected, whereas males with asymmetrical greetings show the opposite pattern (DeVore 1962, as described in Smuts and Watanabe 1990:165). Second, when two or more male baboons attempt to form an aggressive coalition, they solicit one another's aid by "head-flagging" (a rapid turning of the head back and forth from the potential ally to the opponent) (Packer 1977) in combination with brief, telegraphic versions of some of the same postures employed in greeting rituals. In particular, allied males often present their hindquarters to one another, and the rapid hip-grasping and mounting that occurs in response seems to help synchronize their joint threats against a common rival (Packer 1977; Ransom 1981; Smuts 1985). We suggest that such telegraphic usage may hearken back to agreements already achieved during routine greetings.

Finally, a single anecdote suggests the possibility of retribution against defectors. One day, Alex and two other old males engaged in prolonged harassment of a young male in consort with an especially popular female. Over and over they charged the consorting male, but he managed to hold his ground. Finally, after several hours, Boz (who had been off by himself foraging) appeared on the top of a smill rise from which he surveyed the scene below. The coalition partners simultaneously solicited his participation through the standard method of head-flagging. Boz charged down the hill toward them, and the consorting male lost his nerve and ran away. Boz's greater momentum carried him closest to the female, and he then began to move off with her, as if to form a new consortship. Alex caught up with Boz and hurled himself on top of his friend with such force that they both collapsed onto the ground. Boz stood up and walked away, leaving Alex with the female.

Such direct interference with a consorting male is virtually unheard of in baboons, presumably because under normal circumstances it risks escalated aggression that can leave both males seriously wounded (Smuts 1985:152153). In this instance, it appeared to us that Boz cheated when he took the female, because unlike the other males, he had invested little in this particular coalition. Alex responded to Boz's defection with what looked like righteous indignation, and Boz responded to Alex's retribution in a way that appeared simultaneously to acknowledge his defection and the fact that he valued an ongoing cooperative relationship with Alex more than the opportunity to consort with this particular female. The anecdotal limits of this account reflect perhaps as much the rarity of stable male alliances as defections between such allies. We hope future research will follow up our admittedly speculative interpretation of these events.

\section{The Ritual Aspects of Greeting}

Formally, these greetings fulfill Rappaport's criteria for ritual: although baboons obviously lack articulated notions of truth or sanctity, the male greetings conform to a limited set of possible gestures clearly framed by the distinctive combination of exaggerated approach, vocalization, and facial expression. The variability of when to greet and with whom, the indeterminacy of who will do what (if anything) to whom, and the neutral social context of the greetings, all suggest their volitional rather than instinctual nature. In order even to attempt a greeting, both males must accept the constraints of the greeting's outward form so that each can recognize the other's actions as a greeting in the first place. At the same time, acceptance of the greeting's form by no means obliges either male to accept a particular role in any given greeting.

Consequently, the actual completion of a greeting does convey a message, however minimal, to the greeters about their willingness to "play by the rules" in the context of greeting. The possibility of breaking off the greeting at any time also provides an incremental mechanism for testing another male's willingness to cooperate while minimizing one's own investment in the relationship. In this sense, the greetings provide males who might benefit from cooperation with the opportunity to express their good intentions in a world of otherwise unpredictable, highly competitive individuals. This in turn may raise the possibility of 
cooperation or social coordination in other situations, while, conversely, an incomplete greeting clearly indicates a current lack of mutuality. ${ }^{6}$ Here again, as Rappaport argues, the disambiguating function of ritual's form and performance means that the "very limitations of display ... enhance [the] clarity" of any messages conveyed within it (1979b:199).

The greetings also foster interactions between male baboons by simplifying, clarifying, and making more frequent their encounters. Significantly, Robert Axelrod's (1984) study of the evolution of cooperation reveals that effective cooperation in a universe of autonomous, self-interested individuals involves precisely these features of simplicity, clarity, and frequency. According to Axelrod, a robust strategy of cooperation should be friendly but firm, forthright but forgiving - that is, initially willing to cooperate but quick to punish defectors by ceasing to cooperate; clearly consistent about when not to cooperate but ready to reestablish cooperation with defectors once they prove willing to mend their ways. Regardless of strategy, however, Axelrod also demonstrates that cooperation can only evolve when the future looms large enough-that is, when the chance for repeated interactions within partnerships of indefinite duration make the long-term payoffs of cooperation outweigh the short-term temptation to cheat on partners (1984:128-129). Ritual elegantly establishes a context in which to build cooperative relations: its formalism simplifies and disambiguates interactions; its invariance provides a model for reliability and trust-and ultimately truthfulness - and its self-referential nature poses minimal risks but makes possible further commitment with each successful repetition.

Closer consideration of the specific gestures involved in the greetings further suggests their role in facilitating cooperation. The greeting gestures themselves hold clear associations with two primary social relationships in baboons-lip-smacking, embracing, and nuzzling from the mother-infant bond; and presenting hindquarters, grasping hips, mounting, and genital contact from heterosexual mating relationships. ${ }^{7}$ While male-male greetings may indeed relate to the reproductive interests of the males involved, they do not directly entail either nurturance or sex. Why, then, employ maternal and sexual gestures? Evolutionarily, sex and mother-offspring bonds constitute paradigmatic, indeed universal, baboon social experiences. While baboon mothers and infants have their conflicts (Altmann 1980; Nicolson 1982), the baboon mother-infant relationship entails a greater overlap in evolutionary interests, and therefore greater mutuality, than any other social relationship. Similarly, baboon sexual relationships involve males typically twice the size of their female partners who can and do inflict injuries on females in other contexts (Smuts 1985:87-102). In order to copulate, the male must reassure a wary female of his nonaggressive intentions sufficiently to elicit her voluntary participation. ${ }^{.}$
In seeking to establish nonagonistic interaction and communication in a different context, males may well borrow the greeting gestures they do for three reasons. First, sex and mothering represent universally experienced, and thus readily recognizable, relations of mutual interest and affiliation in baboon society. Second, these relationships necessarily entail a significant degree of cooperation and trust. Third, they also involve power distinctions. Mothers dominate their infants, and in sexual relations male baboons dominate their female partners, so greeting gestures can also betoken social asymmetries, as in those greeting dyads in which one male usually adopts the presenting role while the other usually adopts the mounting role; or conversely, they can convey the absence of such asymmetries when they become reciprocal, as in the greetings between Alex and Boz. ${ }^{9}$ Male-as well as female, juvenile, and infant-baboon greetings may thus take the specific form that they do, not simply because these gestures are necessarily instinctual or because they deal directly with mothering or sex. Instead, to the extent that such gestures become freed from their original context to convey related, but by no means identical, social meanings, baboon greetings might even be said to entail rudimentary symbolic communication. That is, baboons may evidence in their greetings the ability to conventionalize acts and interactions as something other than what they manifestly appear to be.

\section{Individuals in Society}

Our study of baboon greeting rituals suggests a way to generalize Rappaport's formal account of ritual's role in generating sanctity and truth in symbolic communication. Ritual also fosters interindividual agreements and trust in the wider context of social cooperation, which evolutionarily-and logically-must precede symbolic communication as the intensified form of social cooperation that it is (among other things). Consequently, Rappaport's formulation enables us to move theoretically in two, seemingly opposite, directions to resolve the chicken-or-egg conundrum in individualist versus culturalist paradigms for explaining society and culture. On the one hand, it enables us to discern in the baboon greetings how individuals might come to convey their intention to cooperate with each other in the absence of articulate speech while also suggesting how deeply rooted such conventionalized communication may lie in our phylogenetic past. On the other hand, as Rappaport himself so ably argues, precisely because the cooperative act of symbolic communication enables-indeed demands (cf. Wagner 1981)-individuals' continual invention of new meanings, ritual's speechless form and performance persist within already established systems of symbolic communication as a way of defending ourselves from the arbitrary power of our own symbolic formulations to imagine alternatives, sanctify the inappropriate-and intentionally lie (Rappaport 1979c). 
Evolutionarily, Frans de Waal (1996) sees the antecedents of human conventionality, and thus morality, in social abilities and propensities common to monkeys and apes, among them prescriptive social rules; interchanges based on concepts of giving, trading, and revenge; moralistic aggression against violators of expected reciprocity; reconciliations after fights; and accommodation of conflicting interests through negotiation (de Waal 1996:211). Research clearly demonstrates that this wide variety of cooperative relationships contributes significantly to individual survival and reproduction among nonhuman primates. ${ }^{10}$ De Waal (1996) further reminds us that such extensive cooperation depends on the ability to maintain friendly relations with other group members in the face of inevitable conflicts of interest. In highly cooperative societies like those of baboons and chimpanzees, social interactions come to be governed as much (if not more) by relational imperatives as by individual self-interests, and mutual agreements achieved through reciprocal "persuasion" often replace exploitative expectations arising from asymmetrical "coercion" (1996:173, 190-191). Thus, "cooperative relationships depend on trust that the other parties will act in a particular way under particular circumstances; troublemakers have difficulty gaining such trust" (1996:170)."

We have argued why ritual should play a critical role in fostering such trust by establishing conventionalized ways of expressing individual intentions to others. Such intentionality remains problematic given the opacity to others of individual motives and the range of alternative behaviors available to any given individual. The voluntary submission to ritual's form-itself perhaps modeled primordially on gestures drawn from still more basic interindividual relations of mother-infant bonds or sex-represents a willing choice in the face of alternative possibilities that then enables other individuals to perceive that behavior as a choice, and therefore as rudimentary social action in Weberian terms - that is, as a mutual interaction that conveys a meaningful intent while taking into account the presumed intentions of others. Once this possibility exists, the latitude of individual action can increase through further commitments to others, actual cooperation with them, and, in turn, greater conscious intent-and, paradoxically, more purposive manipulation of others. Ironically, by becoming more social, individuals simultaneously become more individually inventive. At the same time, such inventiveness requires playing by the rules at least often enough to maintain some minimal credibility: to remain effectively inventive, individuals must act responsibly social.

Out of such struggles for social trust eventually evolved symbols, language, and equally problematic strivings for cultural truths on which to affirm the otherwise arbitrary, and therefore manipulable, associations intrinsic to symbolic comnunication. Once signs no longer hold any necessary relationship to what they signify, anything can come to stand for anything else, and symbolic communication risks foundering on the evils of lie and alternative (Rappaport 1979c). Ritual thus comes into play again, no longer simply to promote interindividual trust but also, on this newly emergent level, to validate the mutual conventions, and ultimately symbols, that social trust has made possible. Just as ritual first came iconically to capture interindividual intent, it now bestows its invariance iconically on the symbolic associations embedded in it as a way of making them certain and thus unquestioned-and therefore appropriate as the paradoxical transcendent ground on which other symbolic associations may be sanctified.

although the concept of the sacred and the notion of the divine would be literally unthinkable without language it may also be that language and social orders founded upon language could not have emerged without the support of sanctity... I have therefore argued that if there are to be words at all it is necessary to establish The Word, and that The Word is established by the invariance of [ritual]. It may at least be suggested, furthermore, that it emerged phylogenetically as some expressions drawn from the burgeoning language of the earlier hominids were absorbed into, and subordinated to, the invariance of already existing nonverbal rituals which seem to be common in the animal world. [Rappaport 1979b:210-211, emphasis in the original]

Rappaport's formal account of ritual thus provides a powerful, unitary framework for conceptualizing the evolution of symbolic communication as an intensification of already existing patterns of social cooperation. This framing obviates any purely individualist versus culturalist explanations of social and cultural life because it reveals the abiding issue to be not one of the Individual as opposed to Society but of individuals in society. If anything we have said about male baboon greetings holds merit, it would suggest that no pristinely autonomous hominid individuals ever existed from which human societies eventually derived or to which human sociality may ultimately be reduced in some primordial regression. Instead, protohuman individuals had already long enmeshed themselves in networks of social cooperation mediated by ritual, which, once established, inevitably became contagious-or, perhaps more accurately, self-escalating - as an evolutionarily stable strategy impervious to invasion by purely self-interested alternatives (cf. Axelrod 1984; Boyd and Richerson 1990). Conversely, Rappaport reminds us that even sacred symbols do not exist simply in and for themselves. Instead, ritual links them to the larger problem of society itself, not in any necessary or functionally reductionistic sense but in an evolutionary-and therefore contingent-sense of having emerged in relation to the problem of reaffirming and intensifying social cooperation between self-interested individuals.

With all this in mind, it makes sense why an otherwise highly competitive and testy male baboon should ever allow another male literally to hold his future reproductive 
success in the palm of his hand. It is hard to imagine a more tangible expression of trust than to invite excruciating punishment for a real or perceived slight or betrayal; conversely, each time males greet with restraint, they demonstrate their trustworthiness (cf. Zahavi 1977). We should also not be surprised to find that an analogous association between pledging and penises exists in human societies. Among the Walbiri of central Australia, men from different communities express their willingness to support each other through a public presentation and grasping of the supplicant's subincised penis (Meggitt 1965:262). ${ }^{12}$ Similarly, in Genesis (24:9), Abraham's servant swears an oath while placing his hand under his master's "thigh," a probable euphemism for the genitals (cf. The New English Bible 1976:22n.; The New Oxford Annotated Bible 1991: 29n.). And finally, the Oxford English Dictionary (1989) suggests that "testicle," "testify," and "testimony" may share the same Latin root testis, meaning "witness," a possible reflection of the Roman practice of a man swearing to tell the truth by touching his forefinger to his testicles to call down upon himself "sterility or lack of posterity" if he lies (Burke 1982:452). Of course, Australian Aboriginals are no more baboons than they are Old Testament prophets - and certainly none of these three understands Latinbut their very incongruity suggests an enduring nexus in ritual between formalized acts and expressed intent, willful individuals and social promises, fragile trust and ever elusive truths.

\section{Conclusion}

Having stretched our credibility this far, it should now be relatively easy to demonstrate the wider relevance of Rappaport's work for the anthropology of religion. In his classic The Elementary Forms of Religious Life, which has shadowed so much of the anthropology of religion, Émile Durkheim (1995:92) singled out Australian Aboriginal totemism, not because he sought the primordial origins of religion but because he believed that a single "well-conducted" experiment on an exemplary case could shed light on all religious life as an essential constituent of human society. In recent years, however, ethnographic thought experiments in the anthropology of religion have turned increasingly toward culturally and historically particular problems-first through symbolic, structuralist, and interpretive approaches, then Marxist inquiries into the ideological nature of religious forms. Most recently, postmodern fashions have delighted in the indeterminacies, and thus politics, of symbolic representation and culture as the performance of self and society.

These approaches have quite rightly drawn our attention to, then enabled us to address systematically, the myriad details and diversity of religious conceptions, practices, and power. Their ability, however, to engage us in particular local systems of meaning, global histories of colonial or postcolonial domination and resistance, and now transnationalized cultural predicaments and pastiches continually tempts us to explain these developments in their own terms as elements within larger wholes, however these come to be defined in symbolic, historical, or political terms. The very richness of these approaches ironically risks explaining religion away without really explaining it, if only because they postpone, if not reject outright, the search for generalizations across their historically particular, culturally relativized case studies, however globally situated.

In contrast, Rappaport's theory of ritual persuasively demonstrates that explanation demands not simply discerning (or despairing over) symbolic meanings but also accounting for how something as improbable as symbolic communication ever evolved in the first place. While evolutionists and cultural anthropologists tend to dismiss each other as simpleminded reductionists or muddle-headed mystics, this article-like Rappaport's work in general-has sought to articulate a middle ground that does equal justice to the emergent evolutionary processes and problematic conventional constraints that characterize human cultures.

Ironically, it was Clifford Geertz, one of the most eloquent and influential of "anti anti-relativists" (as he so characteristically put it) (Geertz 1984), who long ago noted the relationship between human evolution and culture. In 1966 , he proclaimed in a now classic essay on "The Impact of the Concept of Culture on the Concept of Man" that humanity is literally nothing if not culturally diverse (Geertz 1973a). He dispensed with what he called the "stratigraphic conception of man" as a layering of biological, psychological, social, and cultural components by arguing that the human species did not first evolve biologically then acquire the cultural trappings of thought, feeling, and language. Instead, the most recent stages of human evolution attest to a long

overlap . . . between the beginnings of culture and the appearance of man as we know him today.... What this means is that culture, rather than being added on, so to speak, to a finished or virtually finished animal, was ingredient. and centrally ingredient, to the production of that animal itself. . . By submitting himself to governance by symbolically mediated programs for producing artifacts, organizing social life, or expressing emotions, man determined, if unwittingly, the culminating stages of his own biological destiny. Quite literally, though quite inadvertently, he created himself. [Geertz 1973a: 47-48]

The lesson Geertz draws from this coevolution of human biology and culture is that, because culture has played such an essential role in human evolution and because human cultures remain so irreducibly diverse, what holds most generally true for all human beings resides not in any substantive behavioral universals that underlie (or transcend) human cultural diversity but in the systematic ways human individuals become the diversely cultural (and 
personally idiosyncratic) beings they are. Precisely because we have evolved into a species that biologically leaves us so behaviorally plastic, and thus so desperately dependent on learned culture to complete ourselves, human beings remain as culturally diverse in their essence as in their expression. Consequently, the only admissible generalizations about human beings must come from seeking "systematic relationships among diverse phenomena, not substantive identities among similar ones" (1973a:44) that is, from an ethnography that generalizes within cases, not between them (Geertz 1973b:26). For the last thirty years, much of sociocultural anthropology, but especially the anthropology of religion, has complied.

In contrast, another way to read Geertz's insight into human biological and cultural coevolution is to recognize not simply an intrinsic human cultural diversity but also an abiding species unity in that, however diverse their expression, protohuman cultures must have all worked similarly on protohuman organisms in the course of human evolution to produce a single species so utterly dependent on having one culture or another. That is, alongside their undeniable symbolic distinctiveness, cultures undoubtedly possess an equally undeniable, formal substantive unity in the way their symbolically constituted orders work on their adherents - and demand that these adherents continually work on their culture--in order to make human social engagement possible.

Given Geertz's compelling argument that human evolution has inextricably meshed our biological and cultural selves, his "systematic relationships among diverse phenomena" must pertain to more than simply how all cultures (or individuals) differ in similar ways. They must also include how all human individuals have come to relate similarly to their diverse (and often multiple) cultural worlds. Neither empty nor pointless, such formal abstractions-or at least the tacit assumption of formal equivalents across abiding cultural diversity-are indeed what make anthropological humanism and relativism possible in the first place. Without some kind of (even implicit) formal comparability to rationalize it, anthropology's championing of cultural diversity as expressive of a common humanity would make absolutely no sense at all.

It is Roy A. Rappaport's lasting contribution to the anthropology of religion-and to anthropology in generalthat he situates ritual precisely at this juncture between embodied acts of individual behavior and the disembodied meaningfulness of sacred, as well as mundane, symbols. By refusing to grant priority to either behavior or meaning, he explains neither away and reveals how better to explain both in terms of each other as the "diverse phenomena" they are. Despite all the accusations leveled against him of being the grossest kind of functionalist (cf. Friedman 1974), Rappaport knew that, in pointing out the ecological functions of Tsembaga Maring ritual, he also had to ask why the Maring fulfilled these functions through rituals rather than in some other way. From a preliminary discussion in Pigs for the Ancestors (1984: 233-237), he pursued this more difficult, and speculative, question to his insights into ritual's form and performance and how sanctity arises from these. He could thus demonstrate that in its ability to establish the possibility of trust and truth in a social world of willful beings and arbitrary symbols, ritual may indeed have no functional equivalent. It persists, and therefore finds its explanation, in the ultimate incommensurability of individuals and the social conventions that underwrite their individuality - a contradiction that continues to plague us (and perhaps our primate contemporaries) no less than it bedeviled our protocultural hominid ancestors.

Far from the empty categories that Geertz once took any generalization about our common humanity to be, Rappaport reminds us that a formal and logical model-Durkheim's one well-conducted experiment-can indeed meaningfully relate the most particular in religious formulations to the most enduring human problems of how society emerges from individuals, morality from self-interests, trust and truth from suspicions, lies, and deceit. No simpleminded functionalist, let alone vulgar materialist, Rappaport's progress from innkeeping to pig feasts, from cybernetics to sanctity, from adaptive disorders to the anthropology of trouble (cf. Rappaport 1979a, 1993), bears eloquent testimony to a deeply thoughtful, thoroughly committed human being, never satisfied with easy answers, always aware of what his formulations left unexplained, and therefore ever-loath to explain anything away while deeper, more difficult questions remained to be answered.

\section{Notes}

Acknowledgments. An earlier version of this paper was read as part of the panel "Roy A. Rappaport Retrospective: Assessments and Appreciations" at the annual meetings of the Political Ecology Society and the Society for Applied Anthropology, Seattle, Washington, March 7, 1997. We thank Aletta Biersack for organizing the panel, inviting us to join it, and for helpful comments in revising the paper. We also gratefully acknowledge the support we received from the National Science Foundation, grant BNS-83-03677, Irven DeVore principal investigator, and in Kenya from Jim Else of the Institute for Primate Research and Shirley Strum, codirector of the Gilgil Baboon Project. Joab Litzense and above all Josiah Musau and Francis Milili provided invaluable aid in the field that made our study possible and warmly rewarding. In addition. Watanabe acknowledges support from the National Endownent for the Humanitics and the Dean of Faculty at Dartmouth College for a fellowship at the National Humanities Center, Research Triangle Park, North Carolina, where he comipleted his final revisions on this essay. He also wishes to thank Hoyt Alverson and Hans Penner for close and contested readings of an earlier draft that scrved to sharpen presentation of the argunent. along with Edward F. Fischer whose conıments helped do the same. Snuts wishes to thank R. W. Smuts for perceptive feedback on an earlier draft. As belore, the text makes clear why 
we remain indebted to Irven DeVore and Roy Rappaport, but no one else should be held to account for what we have done with their inspiration or counsel.

1. Here Rappaport obviously follows Durkheim's theory of ritual and religious sentiments as inherently social rather than psychological. Despite long-standing dismissal of Durkheim's theory of the origins of religion as "crowd psychology" (cf. Evans-Pritchard 1965:67-68; Lévi-Strauss 1963:70-71), Durkheim's argument remains more cognitive than emotional, centered on the way in which religion focuses and channels collective sentiments that already exist in individuals simply by virtue of their contrasting experience and perceptions of a social versus a natural world:

the [social] environment in which we live seems populated with forces at once demanding and helpful, majestic and kind, and with which we are in touch. Because we feel the weight of them, we have no choice but to locate them outside ourselves, as we do for the objective causes of our sensations. But from another point of view, the feelings they provoke in us are qualitatively different from those we have for merely physical things.... The two sorts of representation form two kinds of mental state, and they are as separate and distinct as the two forms of life to which they correspond. As a result, we feel as though we are in touch with two distinct sorts of reality with a clear line of demarcation between them: the world of profane things on one side, the world of sacred things on the other. [Durkheim 1995:214]

It is this preexisting conscience collective on which the "effervescence" of collective rites works. Interestingly enough, Rappaport, following Eric Erikson. would root such social awareness most incipiently and tangibly in the early dependency of infants on their mothers-an ontogenetic (if not phylogenetic) dyadic relationship (Rappaport 1979b:2 I2).

2. The study resulted in nearly 100 hours of focal samples of the 12 fully adult males in the troop, combined with ad libitum (free or nonfocal) observations, which produced 637 greetings among adult males. For each greeting, we recorded the identity of the two males, the context in which it occurred, the precise gestures or movements exchanged during the greeting, and the sequence in which they occurred. We then analyzed variations in the pattern of greetings relative to the males involved. For further information about methods and results, see Smuts and Watanabe (1990). Greetings occurred twice as often as any other kind of interaction between adult males. Significantly, however, successful initiation of a greeting never guaranteed its completion. Nearly half the time, one male would pull away and move off rapidly before the exchange was completed; we termed such occurrences "incomplete" greetings.

3. There is no evidence that closely related males (for example, maternal brothers) tend to transfer to the same troop, and thus immigrant males are typically unrelated.

4. It is important to note that not all coalitions among savanna baboon males necessarily entail the level of reciprocity or trust that we have described for Alex and Boz. Sometimes males apparently form coalitions opportunistically with whichever suitable partners appear at hand (Berkovitcl 1988). In some troops, coalitions also involve males of disparate ranks; when this occurs, the highest ranking coulition member typically claims the lemale (Noc 1992). At laast among the olive baboon subspecies, however, different obscrvers have repeatedly described the occasional pair of males with an unusually "advanced" partnership, characterized by a very high frequency of coalition formation, equal access to the fertile females gained through such coalitions, and a strong inhibition against challenging one another's consortships (Berkovitch 1988; Ransom 1981; Smuts and Watanabe 1990).

5. Similarly, in another population of olive baboons, males never inflicted wounds during approximately 400 male-rnale greetings recorded on videotape, but they injured one another frequently in other contexts (Smuts, unpublished data).

6. An interesting example of "current lack of mutuality" occurred during a recent field study of olive baboons at Gombe, Tanzania (Smuts and Gubernick, unpublished data). During the course of the study, a young prime male, Chongo, transferred into the study troop and immediately began to challenge other males. All of the other males except the alpha male, Apie, rapidly deferred to the highly aggressive, extraordinarily confident newcomer by showing submission in agonistic encounters and allowing Chongo to mount them during greetings. Chongo then initiated friendly relations with some of these males by inviting them to mount him. Apie was the only male in the troop who truly equaled Chongo in age, size, canine condition, and social ambition. Chongo avoided challenging Apie directly, but he frequently shadowed him, which clearly made Apie very nervous. Apie repeatedly approached Chongo with greeting overtures, only to veer away at the last minute. Finally, Apie approached Chongo with vigorous lipsmacking, turned around, and lowered his hindquarters in a typical present. Chongo responded by lip-smacking in turn, but as he reached to touch Apie's hindquarters, Apie jumped, turned in mid-air, and landed facing Chongo with his mouth wide open in a high-intensity canine threat display. Chongo immediately responded in kind, the males grappled briefly with their hands, and then Chongo fled, with Apie in pursuit (unless the fleeing male shows submission, which Chongo did not, such chases represent standoffs). The researchers recorded this interaction on videotape and a few days later recorded another virtually identical interaction between the same males. When they examined the tapes in slow motion, they found that in both instances, Chongo had played by the rules and done nothing to provoke Apie's ageression. In real time, however, no human observer, and probably no baboon, could have told that Apie, not Chongo, had cheated by resorting to unprovoked ageression during a normally peaceful ritual. Nothing indicates whether Apie's behavior represented a spontaneous eruption of emotion or a deliberate attempt to provoke Chongo into submission through a surprise attack. Either way, his highly unorthodox behavior demonstrates that males can break the rules during a greeting ritual. thereby highlighting the significance of the peaceful progression of the vast majority of greetings. Apie and Chongo never managed to achicve even rudimentary mutuality in their greetings (perhaps in part because Chongo appeared understandably suspicious of Apie's greeting approaches alter these incidents), and two montlis later, in the face of Chongo's relentless sladowing, Apie lost his nerve and ran away, tail up and screaming, in 
a humiliating display of intense fear and submission. At that moment, Chongo became alpha male.

7. The same elements are also found in male-female greetings, lenlale-female greetings, and greetings involving infants and juveniles (Hausfater and Takacs 1987).

8. Male baboons cannot literally force a female to copulate (Smuts and Smuts 1993).

9. In other mammals as well, submissive greeting gestures often derive Irom behaviors typical of subordinates in other contexts, such as gestures that females display toward males during courtship or that juveniles display toward adults during food-begging. Similarly, dominant greeting gestures relate to behaviors typical of dominants, such as gestures males show toward feniales or that adults show toward immatures (cf. East et al. 1993:364). Evidence from spotted hyenas provides an informative variation on this theme. Spotted hyenas are exceptional among mammals in that females consistently dominate males and behave more aggressively; in addition, females possess a "pseudo-penis" (as a result of unusually high androgen levels) almost indistinguishable from a true penis. During greetings between females and between females and males, the subordinate member of the dyad (always the male when the dyad is heterosexual) uses an erect "penis" to indicate submission. In contrast, in all of the other (male-dominant) mammalian species that use the erect penis as a social signal, the display connotes dominance (1993:364).

10. Cooperation occurs in a wide variety of contexts including but not limited to: hunting, foraging, food-sharing, vigilance against and protection from predators, breaking up of fights (de Waal 1996), protection of immature animals from conspecifics, aggression against other group members, and aggression against other groups (Smuts et al. 1987; see also Harcourt and de Waal 1992, McGrew et al. 1996).

11. Similarly Robert Axelrod also notes, "A community using strategies based upon reciprocity can actually police itself. By guaranteeing the punishment of any individual who tries to be less than cooperative, the deviant strategy is made unprofitable. Therefore, the deviant will not thrive, and will not provide an attractive model for others to imitate" (1984: 138). Ironically, however, he also points out that fostering such reciprocity involves "enlarging the shadow of the future" by making relationships more durable and frequent, and a "good way to increase the frequency of interactions between two given individuals is to keep others away" (1984:130). As Claude Lévi-Strauss (1985) has argued, the problems of racism, prejudice, and ethnocentrism between human groups may lie rooted in the nature of human social life itself, not simply in ignorance, isolation, or self-serving discrimination.

12. Meggitt writes, "When men Irom another community or tribe arrivc for ceremonies, they usually first perform a penis-offering ritual with their hosts. Each visitor approaches each of the seated hosts in turn and lifts the latter's arm. He presses his penis against the host's hand, so that the subincised urethra is in full contact with the palm, and then firmly draws the penis along the hand. A man with a grievance against the visitor refuses to raise his hand for the ritual. At this sign of hostility, the visitor at once presents his penis to each of his classilicatory 'brothers' anong the losts. Should nonc of his 'brothers' take it, the outsider must be ready to fight or to llee; he knows that public opinion is solidly against him. But at 'brother' who touches the visitor's penis consents to sponsor him and must stand and plead his case. If the appeal fails, he must also fight beside the outsider" (1965:262).

\section{References Cited}

Altmann, Jeanne

1980 Baboon Mothers and Infants. Cambridge, MA: Harvard University Press.

Axelrod, Robert

1984 The Evolution of Cooperation. New York: Basic Books.

Berkovitch, F. B.

1988 Coalitions, Cooperation and Reproductive Tactics among Adult Male Baboons. Animal Behaviour 36:11981209.

Boyd, R., and P. J. Richerson

1990 Group Selection among Alternative Evolutionarily Stable Strategies. Journal of Theoretical Biology 145: $331-342$.

Bulger, J. B.

1993 Dominance Rank and Access to Estrous Females in Male Savanna Baboons. Behaviour 127(1-2):67-103.

Burke, D. G.

1982 Gesture. In The International Standard Bible Encyclopedia, vol. 2. Pp. 449-457. Grand Rapids, MI: William B. Eerdmans Publishing.

Byrne, R. W., and A. Whiten

1990 Tactical Deception in Primates: The 1990 Database. Primate Report 27:1-101.

Darwin, Charles

1872 The Expression of the Emotions in Man and Animals. London: Appleton.

DeVore, Irven $\mathrm{B}$.

1962 The Social Behavior and Organization of Baboon Troops. Ph.D. dissertation, Anthropology Department, University of Chicago.

Durkheim, Émile

1995 The Elementary Forms of Religious Life. Karen E. Fields, trans. New York: The Free Press.

East, M. L., H. Hofer, and W. Wickler

1993 The Erect 'Penis' is a Flag of Submission in a FemaleDominated Society: Greetings in Serengeti Spotted Hyenas. Behavioral Ecology and Sociobiology 33:355-370.

Education Development Center

1965 Dynamics of Male Dominance in a Baboon Troop. Film in the series Man and Other Animals. Newton. MA: Education Development Center.

Evans-Pritchard, E. E.

1965 Theories of Primitive Religion. Oxford: Oxford University Press.

Friedman, Jonathan

1974 Marxisnı, Structuralism, and Vulgar Materialism. Man n.s. 9:444-469.

Geertz, Clilford

1973a The Impact of the Concept of Culture on the Concept of Man. In The Interpretation of Cultures. Pp. 33-54. New York: Basic Books.

1973b Thick Description: Toward an Interpretive Theory of Culture. In The Interpretation of Cultures. Pp. 3-30. New York: Basic Books. 
1984 Distinguished Lecture: Anti Anti-Relativism. American Anthropologist 86:263-278.

Goodall, Jane

1986 The Chimpanzees of Gombe: Patterns of Behavior. Cambridge, MA: Harvard University Press.

Harcourt, Alexander H., and Frans B. M. de Waal, eds.

1992 Coalitions and Alliances in Humans and Other Animals. Oxford: Oxford University Press.

Hausfater, Glenn, and David Takacs

1987 Structure and Function of Hindquarter Presentations in Yellow Baboons (Papio cynocephalus). Ethology 74: 297-319.

Hinde, Robert A.

1974 Biological Bases of Human Social Behaviour. New York: McGraw-Hill.

Huxley, Julian

1914 The Courtship Habits of the Great Crested Grebe (Podiceps cristatus) Together with a Discussion of the Evolution of Courtship in Birds. Journal of the Linnean Society of London, Zoology 53:253-292.

Lévi-Strauss, Claude

1963 Totemism. Rodney Needham, trans. Boston: Beacon Press.

1985 Race and Culture. In The View from Afar. J. Neugroschel and P. Hoss, trans. Pp. 3-24. New York: Basic Books.

Lorenz, Konrad

1950 The Comparative Method in Studying Innate Behaviour Patterns. Symposium of the Society for Experimental Biology 4:221-268.

1966 Evolution of Ritualization in the Biological and Cultural Spheres. Philosophical Transactions of the Royal Society of Britain 251:273-284.

McGrew, William C., Linda F. Marchant. and Toshisada

Nishida, eds.

1996 Great Ape Societies. Cambridge: Cambridge University Press.

Mech, L. David

1970 The Wolf: The Ecology and Behavior of an Endangered Species. Garden City, NY: Natural History Press.

Meggitt, Mervyn J.

1965 The Desert People: A Study of the Walbiri of Central Australia. Chicago: University of Chicago Press.

Moore, J. H.

1994 Putting Anthropology Back Together Again: The Ethnogenetic Critique of Cladistic Theory. American Anthropologist 96:925-948.

Moynihan, $\mathrm{M}$.

1956 Notes on the Behaviour of Some North American Gulls I: Aerial Hostile Behaviour. Behaviour 10:126-178.

The New English Bible. Oxford Study Edition

1976 S. Sandmel, gen. ed. New York: Oxford University Press.

The New Oxford Annotated Bible, New Revised Standard Version

1991 Bruce M. Metzger and Roland E. Murphy, eds. New York: Oxford University Press.

Nicolson, Nancy

1982 Weaning and the Development of Independence in Olive Baboons. Ph.D. dissertation, Anthropology Department, Harvard University.
Nishida, T., and K. Hosaka

1996 Coalition Strategies among Adult Male Chimpanzees of the Mahale Mountains, Tanzania. In Great Ape Societies. William C. McGrew, Linda F. Marchant, and Toshisada Nishida, eds. Pp. 114-134. Cambridge: Cambridge University Press.

Noe, $R$.

1992 Alliance Formation among Male Baboons: Shopping for Profitable Partners. In Coalitions and Alliances in Humans and Other Animals. Alexander H. Harcourt and Frans B. M. de Waal. eds. Pp. 284-321. Oxford: Oxford University Press.

Oxford English Dictionary, 2nd ed.

1989 J. A. Simpson and E. S. C. Weiner, eds. Oxford: Clarendon Press.

Packer, C.

1977 Reciprocal Altruism in Papio arlubis. Nature 265 (5593):441-443.

Ransom, Timotlyy W.

1981 The Beach Troop of Gombe. Lewisburg, PA: Bucknell University Press.

Rappaport, Roy A.

1979a Ecology, Meaning and Religion. Richmond, CA: North Atlantic Books.

1979b The Obvious Aspects of Ritual. In Ecology, Meaning and Religion. Pp. 173-221. Richmond, CA: North Atlantic Books.

1979c Sanctity and Lies in Evolution. In Ecology, Meaning and Religion. Pp. 223-246. Richmond, CA: North Atlantic Books.

1984 Pigs for the Ancestors: Ritual in the Ecology of a New Guinea People. New, enlarged edition. New Haven. CT: Yale University Press.

1993 Distinguished Lecture in General Anthropology: The Anthropology of Trouble. American Anthropologist 95: 295-303.

Rodseth, Lars

1998 Distributive Models of Culture: A Sapirian Alternative to Essentialism. American Anthropologist 100:55-69.

Schenkel, R.

1967 Submission: Its Features and Function in the Wolf. American Zoologist 7(2): 319-329.

Smith, W. John

1977 The Behavior of Communicating: An Ethological Approach. Cambridge, MA.: Harvard University Press.

Smuts. Barbara B.

1985 Sex and Friendship in Baboons. Hawthorne, NY: Aldine Publishing Company.

1987 Sexual Competition and Mate Choice. In Primate Societies. Barbara Smuts. Dorothy Cheney, Robert Seyfarth, Richard Wrangham, and Thomas Struhsaker. eds. Pp. 385-399. Chicago: University of Chicago Press.

Smuts. Barbara B.. and Robert W. Smuts

1993 Male Aggression and Sexual Coercion of Females in Nonhuman Primates and Other Mammals: Evidence and Theoretical Implications. In Advances in the Study of Belavior, 22. P. B. Slater. J. Rosinblatt. M. Milinski, and C. Snowdon, eds. Pp. 1-63. New York: Academic Press. 
Snuts, Barbara B., and John M. Watanabe

1990 Social Relationships and Ritualized Greetings in Adult Male Baboons (Papio cynocephalus anubis). International Journal of Primatology 11:147-172.

Smuts, Barbara B., Dorothy L. Cheney, Robert M. Seyfarth, Richard W. Wrangham, and Thomas T. Struhsaker, eds. 1987 Primate Societies. Chicago: University of Chicago Press.

Strum, Shirley

1987 Almost Human: A Journey into the World of Baboons. New York : Random House.

Tinbergen, $\mathrm{N}$.

1952 "Derived" Activities: Their Causation, Biological Significance, Origin and Emancipation during Evolution. Quarterly Review of Biology 27:1-32.
Waal, Frans de, B. M.

1996 Good Natured: The Origins of Right and Wrong in Humans and Other Animals. Cambridge, MA: Harvard University Press.

Wagner, Roy

1981 The Invention of Culture, revised and expanded ed. Chicago: University of Chicago Press.

Wilson, Edward O.

1975 Sociobiology: The New Synthesis. Cambridge, MA: Harvard University Press.

Zahavi, A.

1977 The Testing of a Bond. Animal Behaviour 25:246247. 